\title{
PRESENTE Y FUTURO DEL DERECHO ROMANO ${ }^{1}$
}

\author{
Javier PARICIO SERRANO \\ Catedrático de Derecho Romano \\ Universidad Complutense de Madrid \\ j.paricio@der.ucm.es
}

a Carlo Augusto Cannata

\section{RESUMEN}

Un ensayo sobre la situación actual y de futuro del derecho romano en el ámbito de la investigación y la enseñanza, y su papel en la formación de los futuros juristas.

Palabras clave: Derecho romano, tradición jurídica occidental, crisis actual del derecho romano, investigación y docencia del derecho romano.

\section{ABSTRACT}

An essay on the actual and future situation of Roman Law in termos of research aswell as teaching, and its role in the formation of future jurists.

Keywords: Roman Law, western legal tradition, present crisis of Roman Law, research and teaching of Roman Law.

\section{ZUSAMENFASSUNG}

Ein Essay über die gegenwärtigen und zukünftigen Situation des Römischen Rechts im Forschungsbereich und im Bereich des Bildungswesens und ibre Rolle in der Ausbildung zukünftiger Juristen.

Schlüsselwörter: Römisches Recht, Rechtstradition des Westens, gegenwärtige Krise des Römischen Rechts, Forschung und Lehre des Römischen Rechts.

1 Texto de la ponencia presentada en la Universidad Carlos III de Madrid, el 23 de junio de 2006, dentro del seminario internacional «El papel de la historia en la formación del jurista europeo», organizado por el Instituto de Estudios clásicos sobre la sociedad y la política «Lucio Anneo Séneca». Al entregar el texto para la publicación he preferido no modificar su factura originaria, por lo que se mantienen el carácter y los límites de escrito concebido para la exposición oral.

Lo dedico, con admiración y afecto que se remontan lejos en el tiempo, a Carlo Augusto Cannata. 
1. Cuando los años veinte del siglo XIX se encuentran aún en sus inicios, Goya, que sobrepasa de largo los setenta años de edad, acaba de hacer una finta a la muerte con ayuda de su amigo el doctor Arrieta, a quien ha pintado curándole. El pintor vive apartado a las afueras de Madrid, detrás del puente de Segovia, al otro lado del Manzanares (en el actual barrio de la Puerta del Ángel), en una casa con huerta adquirida muy poco antes, en febrero de 1819 , y en cuyas paredes había pintado, al entrar a vivir en ella, una serie de paisajes de campo ${ }^{2}$. Superada la enfermedad, superpone sobre esos paisajes unas misteriosas escenas de fuerza alucinante, conocidas luego, por el color predominante y su temática, bajo la denominación global de Pinturas negras ${ }^{3}$, que iban a quedar como uno de los conjuntos pictóricos más asombrosos y más influyentes de la historia del arte. Esas catorce escenas - pues las Pinturas negras son en total catorce ${ }^{4}$ - , nacidas con furia y a velocidad de vértigo, las pinta Goya no por encargo de nadie, ni tampoco para ser mostradas o exhibidas, sino para él mismo, para vivir con ellas, aunque sería por poco tiempo, pues el inicio de la nueva era absolutista de Fernando VII y razones de índole personal le inducirían a donar aquella casa a su nieto Mariano (septiembre de 1823) y, tras unos meses de semiclandestinidad en Madrid, a exiliarse a Francia (mayo/junio de 1824), donde fallecería, en Burdeos, en las primeras horas del 16 de abril de $1828^{5}$.

${ }^{2}$ Sobre este particular, que me había suscitado antiguamente muchas dudas, disipadas cuando hablé con los especialistas sobre la técnica empleada, véase, por todos, C. GARRIDO, «Algunas consideraciones sobre la técnica de las Pinturas Negras de Goya», en Boletín del Museo del Prado, núm. 13, 1984, pp. 6 y ss.

${ }^{3}$ La denominación sólo se generalizaría en el siglo Xx. El abuso del negro es habitual en el pintor en esos años: baste recordar sus dos obras para los Escolapios realizadas en 1919 (Última comunión de San José de Calasanz y Oración en el Huerto), que son también verdaderas «pinturas negras». Que esos años coincidiesen con un prolongado episodio depresivo del pintor es sostenido por el psiquiatra F. ALONSO-FERNÁNDEZ, El enigma de Goya. La personalidad de Goya y su pintura tenebrosa, 2. " ed. (México-Madrid, 2005) passim; este libro, de indudable interés, suscita sin embargo muchas dudas, y algunas de sus afirmaciones deben tomarse con suma cautela.

${ }_{4}^{4}$ Parece que hubo al menos una más, pero en esa discusión no es posible entrar aquí.

5 Según Théophile Gautier, en Burdeos, por aquellos años, «casi todos los letreros estaban en francés y en español», debido al gran número de liberales españoles exiliados que vivían en esa ciudad. La cita de Gautier procede de su libro Voyage en Espagne: Tra los montes, y la tomo de la siempre espléndida biografía de A. VALLENTIN, Goya, trad. esp. de M. de Hernani (1957, nueva edición Barcelona, 1994), p. 357. Pese a que la biografía de Antonina Vallentin no haya perdido su carácter apasionante, es preciso advertir sin embargo que, a la luz de investigaciones más recientes, contiene interpretaciones muy discutibles, e incluso, en ocasiones, insostenibles. 
Aunque no se trate de la más conocida de las Pinturas negras, quizá la más importante de todas ellas sea una enigmática y modernísima pintura de tamaño medio: tras ser trasladada a lienzo mide, aproximadamente, un metro treinta de alto por ochenta centímetros de ancho. De todo el conjunto es una de las menos oscuras y, con toda probabilidad, la que Goya pintó como final de la serie ${ }^{6}$. Por supuesto que se trata de una obra famosa, aunque quizá no tanto, al menos para el gran público, como puedan serlo muchos de los retratos que ejecutó (pongamos por caso el de Jovellanos, el de Bayeu, el de la condesa de Chinchón o el del grupo familiar de Carlos IV), o como las majas o los fusilamientos, pero, pese a su simplicidad formal, es una obra maestra absoluta. Los títulos por los que se la conoce son muy variados ${ }^{7}$, de los que creo preferible el de Perro semibundido ${ }^{8}$, también porque resulta adecuado a las dos lecturas básicas de su contenido: o un perro en lucha contra la corriente que le está venciendo, o, quizá mejor, un perro sumergido y apresado en la arena ${ }^{9}$. Si no todos, supongo que muchos recordaréis de memoria la escena: una cabecita de perro en semiperfil levemente alzada, con mirada entre impotente y suplicante dirigida hacia fuera y hacia dentro, emerge de la zona inferior del cuadro de uniforme color ocre que cubre el cuerpo del can hasta el cuello, mientras que la zona superior - más o menos las cuatro quintas partes del total - viene a quedar ocupada como por manchas de pintura a modo de resplandores de oro viejo de diversas tonalidades. La desnudez de la escena es absoluta ${ }^{10}$, acentuada por la economía de colores. La soledad y la

\footnotetext{
${ }^{6}$ Véase, por todos, P. E. Muller, Goya's «Black Paintings». Truth and Reason in Light and Liberty, New York, The Hispanic Society, 1984, p. 137. Con ella se cerraba el ciclo de la sala superior.

7 Una síntesis sobre los distintos títulos dados a esta obra, en publicación además fácilmente accesible, puede verse en J. J. LunA y M. MORENO DE LAS HERAS, Goya. 250 aniversario, Madrid, Museo del Prado, 1992, pp. 432 y s.

${ }^{8}$ La bibliografía existente sobre esta pintura es abundante, pero, dada la naturaleza de este escrito, no tendría excesivo sentido referirla aquí, ni siquiera la más relevante. Basta, pues, con dejan indicado que una referencia completa y actualizada de la literatura sobre el cuadro puede encontrarse en el sobre núm. 767 de la documentación del Museo Nacional del Prado (Madrid).

9 Recientemente, A. M. ROMERo COLOMA, «Hacia una interpretación de las Pinturas Negras de Goya (homenaje al artista en el 250 aniversario de su nacimiento)», en Boletín del Museo e Instituto Camón Aznar, núm. 69, 1997, p. 219, vuelve a preferir el título indeterminado de «Perro» o «Un perro». En el mismo sentido se manifiesta ahora J. J. JUNQUERA, Las Pinturas Negras de Goya, Madrid, 2003, p. 70.

${ }^{10}$ Las radiografías modernas realizadas sobre la obra descartan incluso distintas interpretaciones antiguas que sostenían la existencia originaria en la pintura de otros elementos,
} 
angustia se palpan casi de modo físico. El perro se encuentra al borde del desfallecimiento, entre el terror y la resignación, como perdido en un desierto de arena y polvo, mientras mira a algo desconocido que no aparece en escena pero que está: de eso al conmovido espectador no parecen caberle dudas.

No estamos aquí —aunque este comienzo pudiera llevar a suponer lo contrario- para hablar de arte, materia en la que yo, y sospecho que casi todos cuantos nos encontramos en esta sala, somos, en el mejor de los casos, poco más que unos diletantes. Si he traído a colación esa pintura, que puede ser interpretada de modos muy diversos ${ }^{11}$, es porque me vino a la cabeza (y soy consciente de que no es la primera vez que lo hace) al ser invitado a participar en esta reunión, y más aún cuando conocí el significativo título genérico que se había dado a la sesión de esta mañana: La fragilidad del jurista y sus necesidades teóricas, al igual que me había venido cinco años atrás al recibir en la Universidad Complutense otro encargo similar a éste relativo a la situación de las llamadas disciplinas jurídicas básicas, y cuyo texto hube de publicar como pequeño libro (que al menos algunos de los presentes conoceréis) ${ }^{12}$ cuando falló el proyecto global en el que estaba enmarcado. No pude evitar entonces, como no he podido evitar ahora, ver encarnado al derecho romano y a la romanística actual en ese conmovedor perro goyesco, casi — sólo casi- aniquilado.

2. En varios de sus escritos más recientes, el último de los cuales - o, al menos, el último que yo conozco- es La idea de Europa, George Steiner ha insistido en una idea tomada de Alfred Horth Whitehead, que éste formulaba de modo ligeramente distinto, y que puede sintetizarse del siguien-

como el cuerpo del perro debajo de la mancha ocre inferior, o un cazador o la cabeza de un caballo bajo la mancha dorada más oscura que cubre el lado derecho: véase C. GARRIDO, «Algunas consideraciones...», cit. en n. 2, pp. 30 y s.

${ }_{11}$ Rafael Canogar, que la ha llegado a considerar esta obra como «el primer cuadro simbolista», después de tantas interpretaciones sobre la enigmática pintura, llega a decir: «¿Qué significa la cabeza de ese perro asomado en ese acantilado, o enterrado en la arena? No se sabe, pero ¡qué más da!, quizá no todo arte deba ser explicable. El historiador del arte Gombrich dice que Goya creaba simplemente imágenes, como si fuesen poemas»: véase R. CANOGAR, «Perro semihundido», en AAVV, Mirar un cuadro en el Museo del Prado, BarcelonaMadrid, 1991, p. 232. Como curiosidad se puede mencionar que un tasador de nombre José Peláez, profesor de Bellas Artes, al estimar en 1855 el valor de las Pinturas negras de cara a la venta de la Quinta del Sordo, refería que «están pintad[a]s en las paredes [de] la sala principal del piso bajo, y encima del piso principal, en número de catorce, y representan varios asuntos que sólo su autor podría calificarlos».

12 J. PARICIO, El derecho romano en la encrucijada, Madrid, 2001; el texto se reproduce también en ID., De la justicia y el derecho, Madrid, 2002, pp. 23 y ss. 
te modo: toda la filosofía occidental no es más que una nota a pie de página al milagro de la filosofía griega ${ }^{13}$. La idea, en su literalidad sólo a primera vista provocadora, podríamos trasladarla ${ }^{14}$ nosotros con igual legitimidad al ámbito del derecho: toda la ciencia jurídica occidental no es más que una nota a pie de página al milagro de la jurisprudencia romana ${ }^{15}$. Y del mismo modo que, como dice Steiner, el ideal socrático del examen de la vida, de la búsqueda de certidumbres trascendentes, o las investigaciones aristotélicas de las problemáticas relaciones entre palabra y mundo, marcaron el camino que mucho tiempo después anduvieron Tomás de Aquino, Descartes, Kant o Heidegger, podemos decir que los juristas romanos, que fueron capaces de crear la ciencia del derecho y su método, marcan la senda que luego transitarían los más grandes juristas europeos, no sólo los iusprivatistas.

Insistir en la importancia histórica del derecho romano, o en la utilidad de su conocimiento como base de la educación de juristas merecedores de ese nombre, apenas si debería consentirse en una sede como ésta. Somos todos, o casi todos, unos convencidos. Nadie de los que aquí nos encontramos ignora que del derecho romano y de su estudio a partir de finales del siglo XI y principios del XII en la Universidad de Bolonia parte la ciencia jurídica moderna, extendida primero por toda Europa y, luego, más allá de nuestro continente. Ninguno de nosotros ignora tampoco que las codificaciones civiles modernas, por decirlo al modo de Cannata ${ }^{16}$, derogaron los textos romanos vigentes, pero para sustituirlos por nuevas leyes - los códigos civiles- que tomaban de aquellos textos el sistema, y no sólo en sus líneas generales, sino también en los detalles; y aunque sea verdad que era mucho lo que había sido modificado y lo que había sido añadido, eso no significa gran cosa, porque modificar y añadir es lo propio en la historia del derecho. Gráficamente señala Cannata que entre las XII Tablas, de mediados del siglo $\mathrm{V}$ a. C. - la primera verdadera codificación de la historia jurídica europea-, y comienzos del siglo II d. C., cuando desarrollan su acti-

${ }_{13}$ Véase G. STEINER, La idea de Europa, con un prólogo de M. Vargas Llosa, Madrid, 2005 , pp. 56 y s.

${ }_{14}$ Ya el propio Steiner la traslada al ámbito religioso con el judaísmo y a, en su opinión, sus dos principales notas a pie de página: el cristianismo y el socialismo utópico, pero no la traslada al jurídico.

${ }^{15}$ La jurisprudencia es «el corazón y el cerebro del derecho romano». Tomo la expresión de M. BRETONE, «La storia del diritto romano e la romanistica come storia», ahora en Diritto e tempo nella tradizione europea, nueva edición puesta al día, Roma-Bari, 2004, p. 265.

${ }^{16}$ Véase C. A. CANNATA, Istituzioni di diritto romano, 1, Torino, 2001, p. 11. 
vidad Celso y Juliano, el derecho, en la misma Roma, cambió mucho más de cuanto lo hizo desde el siglo II hasta hoy. Ninguno de nosotros pone en tela de juicio la utilidad que el conocimiento del derecho romano y la metodología jurisprudencial tienen para la formación de los juristas: entiéndase bien, no simples conocedores o aplicadores de las normas vigentes, sino juristas dignos de ese nombre, y, por tanto, capaces de interpretarlas y aplicarlas con arreglo al sistema de fuentes del ordenamiento jurídico (entre las cuales se cuentan, y muy principalmente, los principios generales), de enjuiciarlas críticamente y de proponer innovaciones en las mismas. Ninguno de nosotros desconoce que estudiar y transmitir el derecho romano como fenómeno técnico, pero storizzato (esto lo expresaba particularmente bien Pugliese), tiene un valor actual, porque no se trata de estudiar y transmitir una experiencia antigua y muerta, sino de estudiar y transmitir la génesis misma de nuestra ciencia jurídica en los contextos sociales y culturales en que nació; y es que el derecho romano es historia, sí, pero historia viva, cargada de vigencia, porque en él están la raíz y el fundamento de lo que ha caracterizado y caracteriza nuestra visión de lo que llamamos derecho. Todo esto son cosas muy sabidas, pero no sólo para nosotros romanistas, pues también lo son para cualquiera que tenga una formación jurídica con alguna entidad y para cualquiera que conozca la esencia de nuestra cultura. Entonces, si eso es así, ¿cómo se explica la crisis más reciente que padece nuestra disciplina en toda Europa, que en los últimos quince o veinte años se nos presenta casi con caracteres de tragedia, con tintes de desmoronamiento que tanto pueden llevarnos a recordar al perro semihundido de Goya?

3. Ante todo, y aunque puedan tener algún fundamento, parece conveniente aparcar habituales respuestas en cierto modo evasivas, del tipo a que «se viven tiempos nuevos», o que «la galopante globalización haría menos necesario el conocimiento del derecho romano». Hace ahora cinco años ya traté (en el escrito antes aludido) acerca de la realidad de una crisis que todos contemplábamos con ribetes inquietantes, y, por eso mismo, desde hacía algún tiempo, era motivo frecuente de conversación entre los especialistas europeos. Al tener que escribir sobre el particular procuré poner el acento en algo que me parecía relevante para entender las cosas y que formulado con brevedad podría sintetizarse así: aunque esta nueva crisis del derecho romano tenga un alcance amplio y aqueje (al menos por lo que a nosotros más nos interesa) a todas las naciones europeas occidentales, las causas de la misma no son coincidentes, o, acaso mejor, no son com- 
pletamente coincidentes, en los distintos países. Quiero decir que no responde a las mismas razones en Francia, en Alemania, en Holanda, en Austria, en Italia o en España. Naturalmente no voy a repetir ahora lo que ya dije entonces, bastándome con indicar que, junto a determinadas circunstancias históricas que más o menos pueden considerarse comunes a los distintos países de nuestro entorno y que no son las más favorables para el desarrollo de materias como la nuestra, en la crisis concreta actual del derecho romano es preciso tener muy en cuenta razones exógenas a la disciplina en algunos países (como sucede en Francia o, más recientemente, en Alemania o en Holanda), mientras que en otros adquieren gran significación las endógenas, como ha empezado a suceder incluso en Italia, pero desde mucho antes, y con una evidencia incomparablemente mayor, en España, que es donde me voy a centrar.

En este sentido, ciñéndonos a nuestro país, sería indecoroso que alguien se atreviera a hablar de la existencia de una política cicatera en el pasado inmediato hacia el derecho romano, cuando basta pensar que en los últimos veinte años el número de profesores numerarios de la disciplina no sé con exactitud si se ha multiplicado por tres, o por cuatro, o por cinco (o incluso por más), fenómeno éste que no debe tener parangón en ningún país de nuestro entorno. Compárese, por ejemplo, con la suerte corrida en el mismo período de tiempo por el derecho romano en Alemania o en Holanda, que viene a ser casi exactamente la opuesta. Sin embargo, pese a esa diferencia nada menor, en todos los países el fenómeno de la «decadencia» se ha producido: en unos, por el motivo principal del arrinconamiento externo padecido por la disciplina; en otros, por, entre otras cosas, haberse desperdiciado de manera lastimosa unas circunstancias históricas irrepetibles, que, de haberse aprovechado, nos podían haber colocado en una situación envidiable en el panorama jurídico y con un peso del que carecemos.

Como aquí estamos en una reunión de romanistas e historiadores del derecho, eludiré una referencia a la situación universitaria española más en general, para centrarnos en nuestro ámbito. Y voy a hacerlo valiéndome de unos párrafos que han visto la luz pocos meses atrás procedentes de un escrito de José Manuel Pérez-Prendes, uno de nuestros máximos historiadores del derecho y que, además, como muchos de vosotros conocéis, posee una extraordinaria formación romanística. Provienen de un artículo que lleva por título el muy significativo de Nil inultum remanebit ( «Nada quedará sin castigo»), y está escrito precisamente en recuerdo de Ursicino Álvarez Suárez, una figura fundacional del moderno romanismo español. 
Pero al aludir a Ursicino Álvarez me vais a permitir que haga un pequeñísimo paréntesis, que, a mi entender, no resulta irrelevante.

En más de una ocasión he manifestado en privado, aunque no tengo ningún inconveniente en hacer pública la reflexión, que no ha sido de trascendencia menor para la suerte del derecho romano en España el que después de nuestra Guerra Civil hayamos carecido en nuestro ámbito de una figura verdaderamente central y aglutinante, equivalente, para que se me entienda, a lo que Joaquín Garrigues fue para el derecho mercantil, o a lo que Manuel Alonso Olea fue para el derecho laboral, o a lo que Eduardo García de Enterría ha sido y es para el derecho administrativo. Obsérvese que no digo que hayan faltado figuras de entidad, sino sólo que ha faltado esa figura grande que abraza a todos (o a casi todos, porque la totalidad roza lo imposible) y a la cual casi todos se sienten vinculados. Quien más próximo estuvo a ese papel fue Ursicino Álvarez, pero determinadas circunstancias que algunos conoceréis, y a las que, en todo caso, no es preciso aludir aquí, impidieron que cumpliese hasta el fondo ese papel central que quizá hubiera provocado que nuestra historia posterior hubiera sido distinta.

Dicho esto, pasemos ya a los referidos párrafos de Pérez-Prendes, cuya persona y obra no precisan de ninguna presentación, y menos aún en un ámbito como éste. Como la cita es larga, mientras no advierta lo contrario es Pérez-Prendes quien habla a través de mi voz ${ }^{17}$.

«Una última reflexión se impone. Esa ineludible necesidad de razones y técnicas, habitual en don Ursicino y su tiempo se ha perdido hoy en muchos libros jurídicos, y yo lo percibo mejor en los histórico-jurídicos, ya sean manuales o monografías. (...) Surge así una supuesta historia del derecho que no es tal. (...)».

«Más grave resulta aún la existencia de redes (no propiamente escuelas científicas) de vulgarización jurídica. Si escribió Wieacker, que "vulgarimo es una categoría histórico-jurídica”, hoy quizá debiera verse en él, más exactamente, uno de tantos heterogéneos basureros que ha ido analizando Gustavo Bueno. A él pertenecen quienes no saben realmente derecho, pero de él viven y dicen enseñarlo. Son los que, como no pueden realizar la que Ihering llamaba áspera tarea de conceptuar, se refugian en la enumeración de datos que no saben interpretar ni por supuesto ordenar. Son gentes abun-

${ }^{17}$ J. M. PÉREZ-PRENDES, «Nil inultum remanebit (en recuerdo de un maestro)», en Seminarios Complutenses de derecho romano, núm. 18, 2005, pp. 208 y ss. 
dantes y peligrosas. Conscientes de que su endeblez científica no soportaría, si fuese descubierta por el público en general, el status social y profesoral que disfrutan (en seguida enumeraré las principales vías por las que lo obtuvieron) saben agruparse entre sí, practican el autoelogio recíproco, y con un tejido de astutas trampas se hacen respetables para la sociedad común. Paradójicamente les protege el discreto desprecio de quienes les conocen mejor».

«Varios han sido los factores propiciadores de esa pérdida de aquella calidad que en mi generación enseñaban maestros como Ursicino Álvarez». Y tras aludir a la reforma de 1970 y a la de 1983 (la LRU, «texto que, por ignorar la textura del cuerpo social al que se dirigía, potenció los mismos males que pretendía evitar»), alude muy concretamente a un curioso fenómeno desenvuelto con fuerza en los últimos años: la aparición de un nuevo género de sujeto: «Se trata de la figura de un agente, dedicado, con lógico éxito (de público, de crítica hablará el tiempo) a la promoción abusiva de un sedicente profesorado de acarreo, integrado por meros solicitadores que ni están ligados con el gestor por vínculos reales de escuela científica, ni exhiben otra sabiduría o título que el discutible de adhesión a la persona que asume introducirlas en cualquier intersicio geográfico de la red estatal del profesorado numerario».

«Otros catedráticos, preocupados más bien por formar unos pocos discípulos con la lentitud, calidad y corto número que esa tarea requiere, resultan así desplazados por un abigarrado cúmulo de gentes, insignificantes pero numerosas, cuya imposible valoración positiva no se logra ni aun disimuladas bajo el corriente término de "macroescuela" (...)».

«Tan diversos, nuevos y constantes flagelos generan un porcentaje ya preocupante de pérdida de la conciencia de la raíz esencial del oficio que nos distingue y justifica socialmente nuestra existencia. Se trata de lo que don Ursicino enseñaba, de la tarea de conceptuar y de seguir el hilo histórico de aparición, transformación y muerte de esos conceptos. Profesores que no pueden cumplir ese básico cimiento de exigencias, no sólo desacreditarán la asignatura que dicen enseñar. El daño irá más allá, engendrarán una pseudociencia que no se disimulará con la obtención por ellos de tramos de investigación, y sólo se encubrirá, gracias a trucos de mercadotecnia, con efímeros reconocimientos sociales durante el tiempo que dure la apariencia de una labor científica inexistente».

«Gravísimo es el efecto de esa enseñanza difundida en los estudiantes de hoy (profesionales de mañana) que no pueden ser conscientes del fraude que sufren, al educárseles en un vulgarismo jurídico análogo al que ahogó el derecho romano. Está así regresando la "franca decadencia" que, con simpático énfasis, describía don Ursicino en sus apasionadas y apasionantes clases de un jurista de alta clase. No es un fenómeno anecdótico ni 
breve; la historia enseña cómo se requieren siglos para salir de esas fosas, y el primer paso será que una historia jurídica seria, pese a ser imprescindible para formar juristas de calidad, se verá rechazada por quienes fueron obligados a estudiar una caricatura de ella. No se puede exigir que todos entiendan que una mixtificación tan enmascarada ha sustituido una pieza conceptual indispensable».

«Sin embargo, las gentes de mi generación tenemos que asumir que no somos inocentes de esos daños. Cuando evoco la enseñanza de don Ursicino, entiendo que él y los otros maestros de su tiempo nos confiaron un legado que no hemos sabido ni defender, ni adecuar, ni transmitir, al menos con la intensidad y coherencia que se requería. Aprovechados oportunistas los ha habido en cualquier momento de la historia universitaria. Si triunfan y predominan es que lo hemos permitido y aún lo seguimos tolerando quienes estábamos obligados a cerrarles el paso. Así quizá condena a nosotros más que a nadie la sentencia que sirve de título a esta evocación de un maestro» (Nil inultum remanebit).

Hasta aquí la cita.

A la luz de unos hechos que Pérez-Prendes describe con tanta fuerza expresiva como plena adherencia a la realidad de las cosas, y teniendo en cuenta que nuestra disciplina sólo puede justificar su pervivencia universitaria por su utilidad, que está en relación directa con la calidad y seriedad científica y docente de quienes la profesan —nosotros no somos civilistas, ni mercantilistas, ni administrativistas, ni laboralistas, ni procesalistas, que no precisan de justificación-, incluso no sería absurdo plantearse de manera descarnada por qué razón deberíamos sobrevivir a nuestras propias acciones suicidas.

En una de las más inolvidables comunicaciones a las que he tenido oportunidad de asistir en nuestro ámbito, presentada por Mario Bretone en un congreso celebrado en Florencia en el otoño de 1991 y que llevaba por título «La historia del derecho romano y la romanística como historia», el romanista de Bari —en un discurso que no era coincidente con este mío de ahora- concluía diciendo, respecto al porvenir de nuestra disciplina, que: «Por desgracia, nosotros no podemos repetir ya la confiada frase de Ihering: "ninguna cosa verdaderamente grande perece en este mundo"» ${ }^{18}$.

${ }_{18}$ M. BRETONE, La storia del diritto romano, cit. en n. 11, p. 279. La cita de Ihering procede de R. vON IHERING, Geist des römischen Rechts, I, 6. ${ }^{a}$ ed., Leipzig, 1907, p. 13 (trad. esp. El espíritu del derecho romano, de Príncipe y Satorres, nueva edición, Granada, 1998, p. 10). 
Dicho de un modo más directo: podemos perecer. La situación de nuestra disciplina en la actualidad, por distintas razones externas y en diferentes perspectivas, es ya de por sí objetivamente precaria: de eso es consciente cualquiera que tenga un ápice de conciencia; pero la ha agravado sobremanera la enloquecida carrera emprendida desde dentro hacia el más absoluto sinsentido. En todo caso, estoy seguro de que las posturas menos válidas de cuantas podemos adoptar son la de lamentarse o la de permanecer expectantes para ver lo que pasa, mientras que una posición mucho más gallarda conduciría a pensar - como ha conducido a algunos, y al decir esto tengo muy presente a Alemania y a Reinhard Zimmermann- sobre qué es lo que debe hacerse, y (con las menguadas fuerzas de que se disponga, pues esas fuerzas serán en todo caso limitadas) actuar en consecuencia.

4. No me resulta posible entrar aquí —y, además, supongo que de hacerlo colisionaría con la exposición posterior de Paco Cuena- a tratar de las orientaciones más recientes de nuestra disciplina en el ámbito de la investigación (y la didáctica), orientaciones que en algunos casos se han visto forzadas por las circunstancias; para ello remito al escrito ya referido del año 2001 donde trato el asunto con concisión.

En todo caso, sí quisiera advertir ahora frente a un riesgo al que ya aludía en aquel escrito. Yo no tengo nada contra la línea lato sensu «cultural», de «grande cultura», de «conoscenza storica del diritto romano» o como calificar se quiera, que tan amplio predicamento tiene sobre todo en Italia; ni mucho menos contra los estudios comparativistas, que tanto auge han experimentado recientemente - $\mathrm{y}$ en las actuales circunstancias aún agregaría que por fortuna, e incluso, si se me permite, que por milagro- al amparo sobre todo del nuevo marco político europeo; ni contra la orientación neopandectista, que en cierto sentido podría contemplarse como una variante de la anterior; ni contra otras posiciones metodológicas. Tengo dicho también que estoy persuadido de que vamos hacia una diversidad cada vez mayor, y que eso no tiene por qué ser perjudicial para la disciplina, siempre y cuando se trabaje con seriedad y rigor, y seamos capaces de poner de manifiesto en nuestras publicaciones y en nuestras clases el interés que el estudio y el conocimiento del derecho romano tiene, desde distintas perspectivas, tanto como elemento insustituible del saber jurídico, como para la comprensión y ayuda a la solución de problemas modernos. $\mathrm{Y}$ eso no se hace teorizando, sino actuando. Pero a lo que iba. En lo que quería incidir - y lo hago sin ningún complejo- es en que, con independencia de la actividad y de la preferencia de cada cual en el ámbito de la 
investigación, es imprescindible para el propio mantenimiento de la disciplina que el estudio histórico del derecho romano en cuanto tal permanezca, y no sólo en la docencia, sino también en la investigación, que tan íntimamente va unida a aquélla. Dicho de otra manera: no debemos avergonzarnos del objeto de nuestro estudio, y, por supuesto, no podemos cambiarlo. Desde que las fuentes justinianeas dejaron de tener vigencia positiva y de tratarse de manera integral y sincrónica (y es bien sabido que el último exponente de relieve fue Alemania, justo hasta finales del siglo XIX), en todos los lugares donde nuestra ciencia se ha cultivado y se cultiva con un mínimo de rigor, el derecho romano ha sido tratado históricamente, lo cual supone, en sentido amplio, conocer su origen, su evolución, y su supervivencia ulterior, sin perder de vista las circunstancias internas y externas que propiciaron e influyeron en su desarrollo. Por consiguiente, para su estudio es necesaria la metodología histórica, como igualmente lo es la metodología jurídica, pues sería imposible estudiar los textos jurisprudenciales romanos o los textos (en sentido amplio) legislativos, desconociendo la dogmática jurídica, aunque de esto último no falten lamentables ejemplos recientes.

Cumplir bien nuestra función como investigadores y como docentes no es tarea fácil, y contemplada desde fuera casi parecería misión de titanes, cosa que desde luego no somos. Resulta indispensable el conocimiento profundo de las fuentes romanas - y señalo de pasada, pero con toda la fuerza posible porque muy a menudo se olvida, que nuestro trabajo tiene que partir de las fuentes y debe estar fundado en ellas, pues éstas no son adornos de las publicaciones, como tantas veces parece-; se exige un conocimiento profundo de la jurisprudencia romana, externo e interno; se exige un conocimiento filológico y de crítica textual; es imprescindible conocer la técnica jurídica; se exige un conocimiento de la historia antigua (y no un conocimiento cualquiera, sino en profundidad), al igual que un conocimiento de la literatura antigua y de la tradición de la misma; y todo ello dejando al margen la epigrafía, la papirología y otras materias. No todos somos iguales, y cada uno de nosotros sabe mejor que nadie $-\mathrm{O}$ debería saber - sus propias limitaciones, pero contando con ellas se nos exige una labor rigurosa; al igual que se nos reclama - y esto también se olvida, por desgracia, con excesiva frecuencia - un rigor máximo en la selección de las personas que vengan detrás y que han de tomar nuestro relevo: una actuación responsable nos debería llevar en este ámbito a ser cuidadosos hasta el extremo. En alguna ocasión he llegado a decir que, en las actuales circunstancias, realizar bien ambas tareas es cuestión de estric- 
ta supervivencia. Y señalo esto persuadido, como estoy, de que, aunque sea porcentualmente pequeño, en España existe hoy un grupo (desperdigado) de romanistas jóvenes más que digno, y romanistas que no son clónicos, sino muy distintos entre sí, y desarrollan su actividad investigadora en las diversas orientaciones de nuestros estudios hoy predominantes en Europa.

5. No soy de natural pesimista, pero no puedo ocultar, y supongo que se me nota, la sensación de desaliento que me produce (y sé bien que no sólo a mí) una situación tan perversa como la que nos envuelve. Como en la película $L a$ boda, del cineasta polaco Andrzej Wajda, creo - y así me parece haberlo dicho también en otras ocasiones- que hubo un momento en que pareció que las cosas podían discurrir por una senda transitable, pero por falta de cuidado y por culpa supongo que de todos —aunque de unos más que de otros, ciertamente-, aquello se desperdició, y dejamos que la sombra negra del «todo vale» oscureciera el presente de entonces y el de ahora, y viciara, de modo difícilmente remediable, el futuro de la disciplina.

No pretendo dar a nadie lecciones de ética ni de justicia, entre otros motivos porque la experiencia es terca al mostrar cómo muy a menudo los comportamientos más torpes suelen proceder de quienes se dedican a impartir lecciones de ese género. En todo caso, en unos momentos como los actuales, es evidente que el sentido de responsabilidad debería tornarse en un deber prioritario para todos. Pero si, dicho eso, me cuesta ser optimista es porque, conociendo la realidad de las cosas, no termino de ver cómo pueda realizarse en la práctica una renovación del tipo que sería necesaria, la cual exigiría, ante todo, un examen de conciencia colectivo, una decidida apuesta por un cambio profundo y una gran generosidad. Digo que no termino de verla, e incluso al formularlo de este modo no hago sino manifestarlo a través de un eufemismo, pero con el máximo deseo de equivocarme.

Entonces, se me dirá, ¿es que no hay esperanza?

Por lo que respecta al largo plazo, aunque uno tenga su propia percepción, no tiene excesivo sentido pronunciarse, al margen de que eso nos introduciría sin remedio en un ámbito tan discutible y desprestigiado como es el de la profecía. Lo que sí debe preocuparnos, en cambio, es el futuro próximo y a medio plazo, y precisamente porque, como decía Pérez-Prendes, la historia enseña que para salir de determinadas fosas puede llegar a requerirse un tiempo demasiado largo. Dicho de otro modo: lo que me preocupa es que pudiera ser aplicable a nosotros la respuesta que Kafka le 
da a su amigo Gustav Januoch cuando éste, angustiado, le pregunta «si es que no hay esperanza», a lo que Kafka le responde que «sí la hay, y en abundancia, pero no para nosotros» ${ }^{19}$. La lucha y, en consecuencia, la esperanza tenemos que mantenerlas: hay que mantener el tipo y los espacios. Pero para que esto no sea sólo retórica, serían necesarias, si no me equivoco, al menos tres condiciones:

Una pertenece al ámbito interno y es categórica: la ya referida de que seamos capaces de encontrar claridad y fortaleza para hacer lo que hay que hacer, estando a la altura que las circunstancias exigen. Complementaria de ella, aunque correspondiente al ámbito externo, sería que la legislación universitaria que de nuevo entra en fase de renovación imposibilite, o al menos dificulte grandemente, que actuaciones como las que hemos tenido ocasión de soportar con horror y vergüenza durante los últimos lustros sigan produciéndose. La tercera - y quizá más importante de todas- es también externa, aunque no sólo externa, y radica en que la asignatura mantenga una posición digna en los planes de estudio de la licenciatura jurídica, pues, como ya he manifestado en alguna otra ocasión, es inútil ocultar que si la marginación del derecho romano se generalizase en la enseñanza universitaria, la disciplina estaría (al menos durante un espacio de tiempo imposible de predecir) en la misma antesala del fin, pues sería ingenuo pensar que pudieran sentirse atraídos a la investigación y la docencia del derecho romano personas de un cierto nivel e inquietud intelectual para ocuparse de una disciplina residual. Que, además, la asignatura se mantenga a modo de pórtico en el primer curso de la licenciatura jurídica es casi una exigencia de la naturaleza de las cosas y algo que me parece innecesario glosar, y menos aún en una sede como ésta.

6. Concluyo. Sabemos que a los romanos antiguos gustaba que lo que había nacido de un modo concluyera del mismo modo: incluso estamos

${ }_{19}$ Parto de una versión referida por George Steiner e incluida en I. Albaret y O. MONGIN, «Herencias y presencia del espíritu europeo. Entrevista con George Steiner», trad. española publicada en Revista de Occidente, núm. 278-279, julio-agosto de 2004, p. 11. Debo advertir, no obstante, que tras una relectura con calma del libro de G. JANOUCH, Conversaciones con Kafka, trad. de R. Sala, Barcelona, Destino, 1997, no he encontrado una correspondencia exacta (aunque sí varias en cierto modo aproximadas) de la cita que hace Steiner, lo cual me induce a pensar, salvo despiste por mi parte, en una no coincidencia de las distintas traducciones (posible no sólo en las de Kafka, sino también en la de la entrevista con Steiner); menos probable es que responda sin más a una cita de memoria, pues, aunque se trate de una entrevista, la referencia aparece entrecomillada y el texto fue revisado por Steiner. Por tanto, no me atrevo a precisar en qué contexto se produjo la manifestación de Kafka. 
habituados a explicárselo a nuestros alumnos a propósito, por ejemplo, del nacimiento y extinción de las obligaciones, partiendo del famoso pasaje del comentario de Pomponio a Quinto Mucio recogido en D. 46.3.80; por eso, vamos a concluir de la misma manera que comenzamos, retornando por un instante al perro semihundido, que a estas alturas se nos ha hecho casi familiar.

En la pintura moderna nadie ha tenido una fijación mayor con el perro goyesco que Antonio Saura, y quizá no sea casualidad que se trate del pintor aragonés más importante desde Goya. Con su lenguaje pictórico tan personal, lo ha reproducido hasta la saciedad en obras de todo tipo: óleos, dibujos, obra gráfica. Sin embargo, Saura no era sólo pintor, sino también un verdadero intelectual, con una obra escrita muy importante, centrada sobre todo, aunque no sólo, en cuestiones artísticas. A mi juicio, las páginas más hermosas que se han escrito sobre el perro semihundido salieron de su pluma, y, las mejores entre ellas, las redactó en un momento de su vida equivalente al que se encontraba Goya cuando lo pintó ${ }^{20}$. Las páginas de Saura, eruditas y de gran elegancia formal, no son en absoluto optimistas, pero en algún momento no dejan de reconocer que la imagen del perro pudiera ser esperanzadora, pues, aunque esté casi hundido, de ello no se sigue necesariamente que el animal sea incapaz de salir de su situación. Ojalá que, en nuestro caso, y siempre que la suerte y los condicionantes externos no sean del todo esquivos, seamos capaces de sortear la situación actual. Ojalá que, en contra de lo que históricamente sucede en tantas ocasiones, las circunstancias y los intereses no conviertan en imposible lo que es necesario.

20 Aunque haga referencia a esa pintura en otros textos, el fundamental es A. SAURA, El perro de Goya, realizado con ocasión de la exposición de Saura en el Pabellón aragonés de la Exposición Universal de Sevilla de 1992, y que se encuentra reproducido en A. SAURA, Fijeza. Ensayos, Barcelona, 1999, pp. 271 y ss.; versión francesa: A. SAURA, Le chien de Goya, Paris, 1996. Antonio Saura falleció, tras una prolongada enfermedad, en su casa de Cuenca el 22 de julio de 1998, cuando contaba sesenta y ocho años de edad. 